training for a senior registrar with special interest, four were set up by a part-time training post for a doctor with domestic commitments and three by another means.

\section{Comment}

Despite local difficulties and restrictions imposed by manpower policies, the response of the profession in providing higher training posts in old age psychiatry has been dramatic, with total numbers trebling over five or six years. Despite this, satisfactory training posts at around $19 \%$ of consultant numbers in old age psychiatry are still less than the $27 \%$ overall in general psychiatry ${ }^{8}$ and the $29 \%$ for general psychiatry excluding old age psychiatry. This is of particular concern when the continuing fast rate of expansion of old age psychiatry ${ }^{3,2}$ and relative undermanning ${ }^{1}$ of the de facto specialty are considered. In this context, the recent initiative of the Joint Planning Advisory Committee 9 in suggesting a further $41 \mathrm{SR}$ posts nationally in general psychiatry but intended predominantly for training in old age psychiatry and the management of substance abuse ${ }^{10}$ is particularly welcome, though careful monitoring will be required to ensure that these posts do in fact go into old age psychiatry and substance abuse in view of the absence of any central data collection method to identify these areas.

\section{ACKNOWLEDGEMENTS}

This work was carried out with the assistance of a part-time research secretary, Meryl Porter, supported by a DHSS grant. Thanks are also due to Valerie Binns of the University of Leeds who assisted with statistical analysis and to all the consultants who patiently completed their questionnaires.

\section{ReFerences}

${ }^{1}$ Watris, J. P. Anatomy of a new branch of psychiatry-Medical manpower and services in old age psychiatry. (In preparation).

${ }^{2}$ JOLLEY, D. (1985) Further developments in psychogeriatrics in Britain. British Medical Journal, 290, 240.

${ }^{3}$ WATtrS, J. P. Geographical variations in provision of psychiatric services for old people. In press.

4_., WAttis, L. \& ARIE, T. (1981) Psychogeriatrics: a national survey of a new branch of psychiatry. British Medical Journal. 282, 1529-1533.

5 _ A ARIE, T. (1984) Further developments in psychogeriatrics in Britain. British Medical Journal, 289, 778.

${ }^{6}$ BLEssed, G. (1986) Survey into the availability of higher specialist training in the psychiatry of old age (November 1985). Bulletin of the Royal College of Psychiatrists, 10, 88-90.

${ }^{7}$ WATtrs, J.P. Anatomy of a new branch of psychiatry-Differences between "specialised" and "non-specialised" psychiatric services for old people. (In preparation).

${ }^{8}$ Medical Manpower Division, DHSS (1986) Career opportunities 1985. Health Trends, 18, 49-56.

'JoInt Planning AdVisory Committee (1987) Report for the Year 1986. London: DHSS.

${ }^{10}$ Royal College of Psychiatrists (1987) Circular letter from President to Regional Advisers in Psychiatry, 29 January 1987.

\title{
The Curt P. Richter Prize 1989
}

\section{Rules and Regulations}

(1) The manuscript should describe original research, or be a review with emphasis on the author's original research, in the field of (Psycho-) Neuroendocrinology.

(2) Only unpublished papers are eligible and the manuscript must be in a format suitable for publication in Psychoneuroendocrinology, the journal in which the winning paper will be published.

(3) Only one author is eligible for the prize. If, for administrative reasons, the paper must bear the names of senior authors, written waiver of consideration for the Prize must be submitted by these authors, concomitant with submission of the manuscript.

(4) The author may not have attained his/her 40th birthday by 1 January 1989.
(5) An original manuscript and five copies are to be submitted to:

Professor Dr Jean J. Legros

Psychoneuroendocrinology Section

CHU (B 23)

Sart Tilman

B-4000 Liege, Belgium

(6) Deadline for submission of manuscripts is 31 January 1989. The prize is awarded traditionally at the Annual Congress of the International Society of Psychoneuroendocrinology, which next year will take place in Buenos Aires, Argentina.

(7) The award includes an honorary certificate and a cheque of US\$1000. 